\title{
Synthesis, electrochemical characterization and molecular dynamics studies of surface segregation of platinum nano-alloy electrocatalysts $\nmid$
}

\author{
E. Favry, ${ }^{a}$ D. Wang, ${ }^{b}$ D. Fantauzzi, ${ }^{c}$ J. Anton, ${ }^{c}$ D. S. Su, ${ }^{b}$ T. Jacob ${ }^{c}$ and \\ N. Alonso-Vante $* a$ \\ Received 3rd November 2010, Accepted 9th March 2011 \\ DOI: $10.1039 / \mathbf{c 0 c p 0 2 3 8 4 a}$
}

\begin{abstract}
Alloy Pt-M (M = Co, Ni) nanocatalysts, supported on carbon Vulcan XC-72, were synthesized using the carbonyl chemical route. A high dispersion on such substrate was revealed by transmission electron microscopy (TEM). Alloy formation on the nanometre scale length was shown by high-resolution transmission microscopy (HRTEM) and energy dispersive X-ray spectroscopy (EDX) on a nanoparticle. The metal M in Pt-M nanoalloys segregates preferentially on the nanoparticles' surface, as determined by the hydrogen adsorption electrochemical reaction. An increased tolerance towards methanol of such nanoalloy materials was observed for the oxygen reduction reaction (ORR) in acid media. To better understand the structure and segregation phenomena of these nanoalloys, molecular dynamics (MD) with a self-optimized reactive force field was applied.
\end{abstract}

\section{Introduction}

The use of electrocatalysts based on platinum, for anodic and cathodic reactions, is very popular. ${ }^{1-7}$ Research has been focused on multi-metallic catalysts in order to enhance selectivity and reactivity. Alloying one or various metals to platinum allows for a modification of its electrochemical properties, and therefore leads to changes in the catalytic behavior as compared to that of platinum alone. ${ }^{8-11}$ In this way, catalytic enhancement of Pt-based catalysts could be positively induced by the second metal and the mechanism may occur through various phenomena, such as (i) electronic effects, which refer to changes in physicochemical properties of the topmost surface atoms, i.e. work function, d-band center position $v$. Fermi level, ${ }^{12}$ d-band occupancy (ligand effects), ${ }^{13,14}$ strain effects ${ }^{15,16}$ that modify the electronic properties via the tensile strain of the surface atoms; and (ii) structural effects, ${ }^{17,18}$ which include correlation between surface atom arrangements, interatomic distances and the statistics of exposed crystal planes as well as statistics of the presence of sites with different coordination numbers at a given particle size. No doubt, all these factors will operate in the course of

\footnotetext{
${ }^{a}$ Laboratory of Electrocatalysis, UMR CNRS 6503, University of Poitiers, 40 Avenue du Recteur Pineau, F-86022 Poitiers Cedex, France.E-mail: nicolas.alonso.vante@univ-poitiers.fr; Fax: + 33 549453580; Tel: + 33549453625

${ }^{b}$ Department of Inorganic Chemistry, Fritz Haber Institute of the Max Planck Society, Faradayweg 4-6, 14195 Berlin, Germany

${ }^{c}$ Institut für Elektrochemie, Universität Ulm, Albert-Einstein-Allee 47, D-89 069 Ulm, Germany

$\dagger$ Electronic supplementary information (ESI) available. See DOI:
} $10.1039 / \mathrm{c} 0 \mathrm{cp} 02384 \mathrm{a}$ reactions making the electrocatalysis and reaction mechanism highly complex. From synthesis point of view, the main methods for preparing multi-metallic catalysts, that are currently used in the field of electrocatalysis, are e.g., colloidal, ${ }^{19-23}$ micro-emulsion ${ }^{24-28}$ and the carbonyl chemical route. ${ }^{29-36}$ The problem with particles of nanometric size is the fact that they are usually not thermodynamically stable and might change over time or during reaction conditions, and corrosioninduced dissolution of alloying components leads to surface roughening. The thermodynamic instability can, furthermore, be due to the excess surface energy, with the result that these particles tend to coagulate, to aggregate themselves or agglomerate at the time of their stabilization, making materials synthesis one of the most important parameters to control. The catalysts reported in this work are bimetallic nanoparticles $\mathrm{Pt}-\mathrm{M}(\mathrm{M}=\mathrm{Ni}, \mathrm{Co})$ synthesized by the carbonyl chemical route. This route of synthesis is rarely used in spite of the interesting prospects that it presents. ${ }^{32,33,36-38}$ In the present work the chemical synthesis and physical-chemical characterization of these nanoalloy materials are combined with theoretical approaches to get more insights into the stability of the catalyst.

\section{Experimental section}

\subsection{Materials synthesis}

The platinum carbonyl, $\left[\mathrm{Pt}_{3}(\mathrm{CO})_{6}\right]_{n}{ }^{2-}(n=10,6,5,4,3,2$, or 1$)$, initial synthesis developed by Longoni et al. ${ }^{29,30}$ was used as a chemical precursor to generate one metal center nanoparticles or alloy nanoparticles: $\mathrm{Pt}_{1-x}-\mathrm{M}_{x}$, where $\mathrm{M}=\mathrm{Ni}, \mathrm{Co}$. In short, $\mathrm{Pt}$ and $\mathrm{M}$-carbonyl complexes were synthesized simultaneously 
using methanol as a solvent through the reaction of Pt and metallic salts with $\mathrm{CO}$ at about $55^{\circ} \mathrm{C}$ for $24 \mathrm{~h}$ with constant mechanical stirring until the solution turned green. The amount of sodium acetate added to the mixture was adjusted so that the sodium acetate/Pt molar ratio was 6 to 1 . The general chemical reaction can be written as:

$$
\begin{aligned}
& (3 / 2) n\left[\mathrm{PtCl}_{6}\right]^{2-}+(3 / 2) n \mathrm{MCl}_{2}+(12 n+1) \mathrm{CO}+(12 n+2) \mathrm{OH}^{-} \\
& \rightarrow\left[\mathrm{Pt}_{3 / 2} \mathrm{M}_{3 / 2}(\mathrm{CO})_{6}\right]_{n}^{2-}+12 n \mathrm{Cl}^{-}+(6 n+1) \mathrm{CO}_{2}+(6 n+1) \mathrm{H}_{2} \mathrm{O}
\end{aligned}
$$

After the synthesis of Pt-M carbonyl complexes, ${ }^{8,39}$ carbon powder (Vulcan XC-72 prior treated under nitrogen at $400{ }^{\circ} \mathrm{C}$ for $4 \mathrm{~h}$ ) is added to the solution, in order to obtain the desired catalyst loading on carbon of $20 \mathrm{wt} \%$. One stage of impregnation of the catalyst onto the support is then carried out by agitating the mixture under an inert atmosphere of nitrogen for $12 \mathrm{~h}$. The powder was recovered, after solvent evaporation, heated at $300{ }^{\circ} \mathrm{C}$ for 90 min under hydrogen atmosphere, and then rinsed with Milli-Q water, in order to eliminate the impurities, such as $\mathrm{NaCl}$, formed during the reaction. Finally, it is dried under nitrogen. The catalysts, with $20 \mathrm{wt} \%$ loading on carbon, were thus: $\mathrm{Pt} / \mathrm{C}, \mathrm{Pt}-\mathrm{Co}(4: 1) / \mathrm{C}$, $\mathrm{Pt}-\mathrm{Co}(2: 1) / \mathrm{C}, \mathrm{Pt}-\mathrm{Co}(1: 1) / \mathrm{C}$ and $\mathrm{Pt}-\mathrm{Ni}(2: 1) / \mathrm{C}$.

\subsection{Physical-chemical characterization}

XRD spectra were obtained at ambient temperature with a Bruker diffractometer D5005, working with the wavelength $K_{\alpha 1}$ of copper $(\lambda=1.54252 \AA)$. The measurements were made on the catalyst deposited as a layer on a silicon wafer (511). The various catalysts were analyzed with TEM and EDX on a Philips CM 120 microscope equipped with a $\mathrm{LaB}_{6}$ filament. The composition of the catalytic particles was examined by EDX with the TEM microscope by using a $10 \mathrm{wt} \% \mathrm{Pt}-\mathrm{Co}$ $(1: 1) / C(E-T E K)$ commercial catalyst as a reference. In order to obtain structural data, the catalysts were further characterized by HRTEM with a Philips CM 200 FEG (Field Emission Gun) microscope. The TEM samples were prepared by ultrasonically dispersing the catalysts in ethanol and then mounting the dispersed particles onto copper grids covered with a holey carbon film and then dried.

\subsection{Electrochemical measurements}

For electrochemical measurements, an ink made up of a catalytic powder, water and Nafion ${ }^{\circledR}$ was deposited onto glassy carbon disks with a catalyst loading of $56 \mu \mathrm{g} \mathrm{cm}^{-2}$ of $\mathrm{Pt}_{1-x}-\mathrm{M}_{x}$. The aqueous phase was eliminated by evaporation under a nitrogen stream. This type of electrode preparation allowed for a diffusion layer thickness smaller than $1 \mu \mathrm{m} .{ }^{24}$ The electrochemical cell employed was a standard one with three electrodes, thermostated at $28{ }^{\circ} \mathrm{C}$, connected to a computer-controlled potentiostat ( $\mu$ Autolab standard II, AUTOLAB). The measurements were done using a mercurous sulfate electrode $(\mathrm{MSE}=0.682 \mathrm{~V} / \mathrm{SHE})$ as reference. Unless otherwise indicated, the results are quoted to the reversible hydrogen electrode (RHE). The current density-potential curves were obtained after some cycles of stabilization in the base electrolyte $0.5 \mathrm{M} \mathrm{H}_{2} \mathrm{SO}_{4}$ and between 0.06 and $1.2 \mathrm{~V} /$ RHE.

\subsection{Theoretical calculations}

The semi-empirical potentials that were used to describe the different interactions between $\mathrm{Pt}$ and $\mathrm{Ni}$ or Co were generated by optimization against a rather extended set of first principles QM calculations. The so-called training-set contained the structures and energies of various pure $\mathrm{Pt}, \mathrm{Ni}$, or $\mathrm{Co}$ as well as mixed systems calculated by the density functional theory. These combined bulk systems, extended surfaces (i.e., slabs), and finite clusters of pure $\mathrm{Pt}$ and $\mathrm{Pt}: \mathrm{Ni}$ or $\mathrm{Pt}: \mathrm{Co}$ alloys, respectively. Details of the systems, which entered the trainingset, can be found in references. ${ }^{40-44}$ Instead of pre-defining the bonds within a system and fixing these connections throughout the simulation, ReaxFF uses the bond lengths to evaluate a bond-order relationship for all connections. This, together with the calculation of pair-wise non-bonded Coulomb and van der Waals interactions for every atom pair, makes the approach capable of investigating structural features as well as simulating bond formation and dissociation processes.

Following the experimental systems, particles with 1.5, 2.0, 2.5 and $3.0 \mathrm{~nm}$ in diameter were generated by cutting spherically-shaped nanoparticles out of $\mathrm{Pt}_{x} \mathrm{Ni}_{1}$ or $\mathrm{Pt}_{x} \mathrm{Co}_{1}$ $(x=1,2,3) f c c$-bulk crystals. Before the actual simulated annealing studies on the changes in particle morphology, each nanoparticle was equilibrated at $300 \mathrm{~K}$ for $12 \mathrm{ps}$ using $0.25 \mathrm{fs}$ time-steps. The systems were then annealed at $1000 \mathrm{~K}, 1250 \mathrm{~K}$, or $1500 \mathrm{~K}$ for $\mathrm{Pt}: \mathrm{Ni}$ and additionally at $750 \mathrm{~K}$ and $500 \mathrm{~K}$ for $\mathrm{Pt}$ : Co with a temperature gradient of $0.05 \mathrm{~K}$ per step until the target temperature was reached, held for $75 \mathrm{ps}$ and then cooled with a temperature gradient of $-0.01 \mathrm{~K}$ per step until the system temperature reached $300 \mathrm{~K}$ again. The relatively high annealing temperatures were applied to give qualitatively different amounts of kinetic energy to the systems allowing them to overcome kinetic barriers involved in structural changes or reorientations, respectively. For each particle size, particle composition, and annealing temperature, a set of 100 different particles were investigated in order to achieve reasonable statistics.

\section{Results and discussion}

\subsection{Structural characterization}

Fig. 1 shows TEM images of hydrogen heat-treated $\mathrm{Pt}-\mathrm{Co}$ $(4: 1) / \mathrm{C}$ and $\mathrm{Pt}-\mathrm{Ni}(2: 1) / \mathrm{C}$ samples. The ratio of platinum to $\mathrm{M}(\mathrm{Ni}$ or $\mathrm{Co})$ is indicated by numbers in $(\mathrm{Pt}: \mathrm{M})$. The particle size analysis of the corresponding samples is displayed in the same figure. The average sizes are $2.40 \pm 1.06 \mathrm{~nm}$ and $2.43 \pm 0.92 \mathrm{~nm}$ for Pt-Co and Pt-Ni particles, respectively.

Similar analyses were also performed on other catalyst particles with different stoichiometries (see Table 1). In spite of the agglomeration that can be induced by the heat treatment, the generated alloy nanoparticles' size is between 1.7 and $3 \mathrm{~nm}$. As summarized in Table 1, the determined alloy compositions by means of EDX are very close to the nominal values. The surface average dispersion, $D$, was calculated using the relation based on the Borodzinski and Bonarowska model $^{45}\left(D=2.64 /\left(d_{\text {rel }}\right)^{0.81}\right) . D$ is a function of the particle size $\left(d_{\mathrm{rel}}=d_{\mathrm{vs}} / d_{\mathrm{at}}\right.$, where $d_{\mathrm{at}}$ is the atomic diameter and $d_{\mathrm{vs}}$ is 

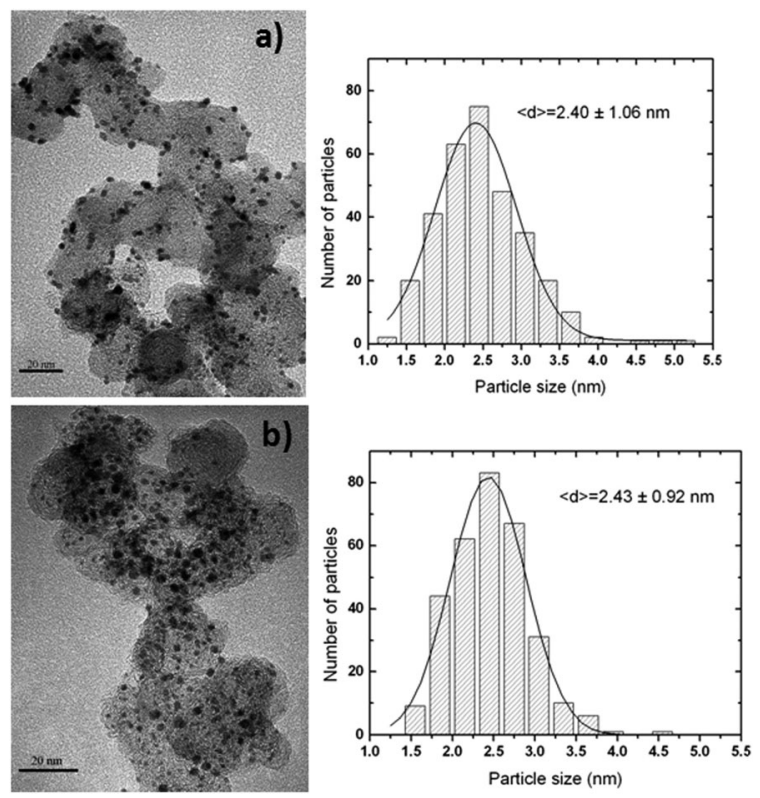

Fig. 1 TEM image and size distribution for (a) Pt-Co $(4: 1) / \mathrm{C}$ and (b) $\mathrm{Pt}-\mathrm{Ni}(2: 1) / \mathrm{C}$. Both catalysts with a loading of $20 \mathrm{wt} \%$.

the mean surface diameter obtained from the particle size distribution for each catalyst).

Fig. $2 \mathrm{a}$ and $\mathrm{b}$ depict HR-TEM images of $\mathrm{Pt}-\mathrm{Co}(4: 1)$ and $\mathrm{Pt}-\mathrm{Ni}(2: 1)$, respectively. The inset in each image represents the fast Fourier transform (FFT) of a single particle in the image. Structural analysis from the FFT indicates that the Pt-Co particle has an $f c c$ structure on its [110] zone axis. The lattice spacing indicated in the image has a value of $2.25 \AA$, which can be attributed to (111) planes. The structure is very similar to that of platinum. A similar structure was observed for the Pt-Ni ( $: 1)$ catalyst as well, as revealed in Fig. $2 \mathrm{~b}$ and the corresponding FFT (see inset). The measured (111) lattice spacing is $2.23 \AA$. In addition, by focusing the electron beam on very small spot sizes, typically $5 \mathrm{~nm}$, EDX spectra can be obtained from one single particle, as shown in the right side of the representative ones for $\mathrm{Pt}-\mathrm{Co}$ and $\mathrm{Pt}-\mathrm{Ni}$ catalysts, respectively. $\mathrm{Pt}$ and $\mathrm{Co}$ lines are visible and most particles give similar spectra. Similarly, in the case of $\mathrm{Pt}-\mathrm{Ni}$ catalyst particles, $\mathrm{Pt}$ and Ni lines are also visible in the spectra of most of the individual particles. This means that most particles in these catalysts are bimetallic and there is strong evidence that they form alloys to keep the $f c c$ structure.

Fig. 3 displays the XRD spectra of $20 \mathrm{wt} \%$ loading of $\mathrm{Pt} / \mathrm{C}$, $\mathrm{Pt}-\mathrm{Co} / \mathrm{C}$ and $\mathrm{Pt}-\mathrm{Ni} / \mathrm{C}$ powders. The spectra obtained are limited to the first two observable Bragg peaks (111) and

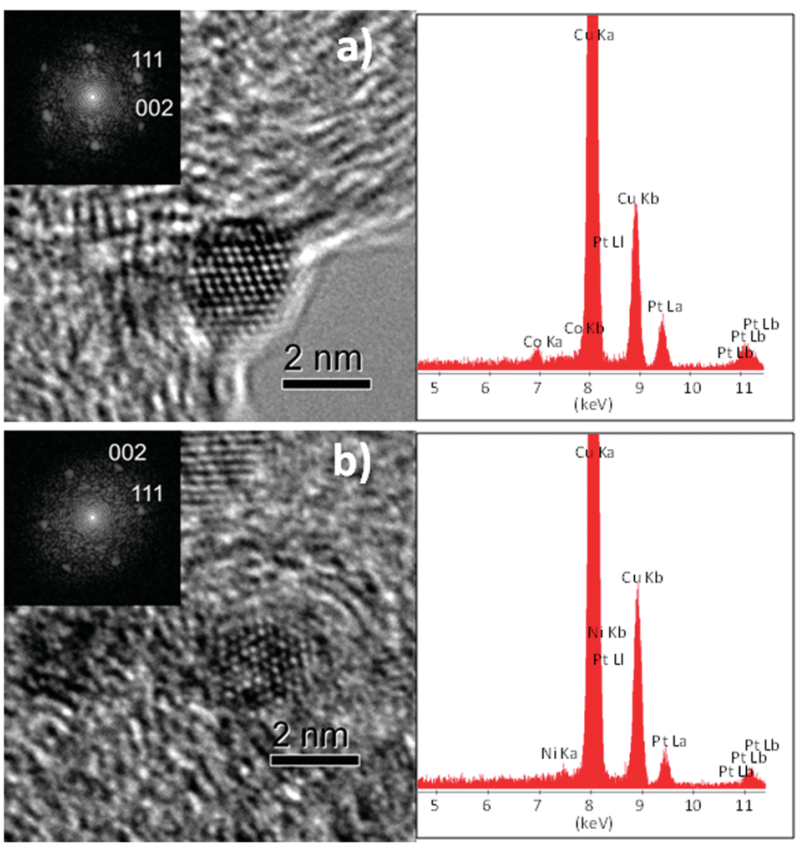

Fig. 2 HRTEM pictures with FFT for (a) Pt-Co $(4: 1) / \mathrm{C}$ and (b) Pt-Ni $(2: 1) / \mathrm{C}$ with a metal loading of $20 \mathrm{wt} \%$ with their corresponding nanoparticle EDX analysis.

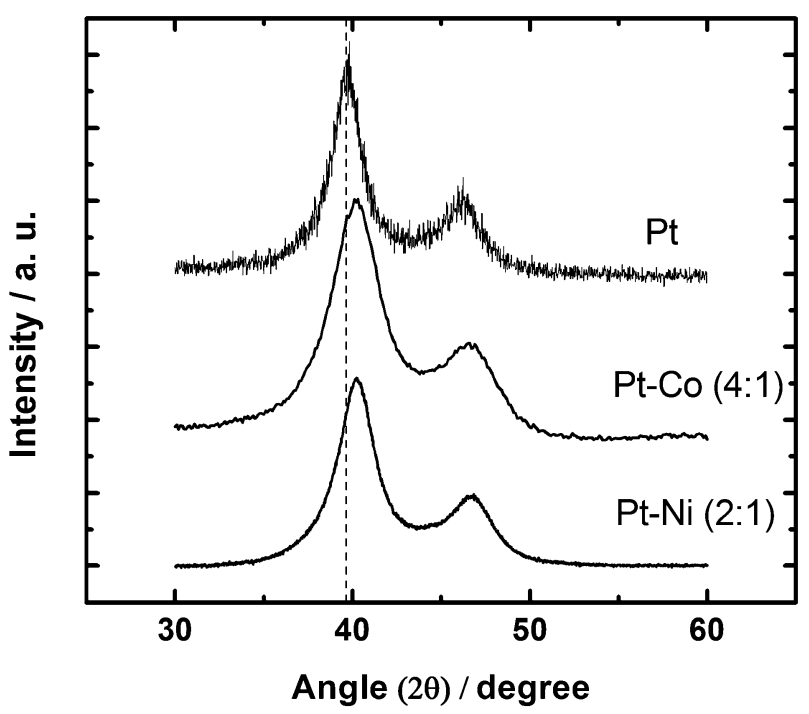

Fig. 3 XRD spectra of $\mathrm{Pt} / \mathrm{C}, \mathrm{Pt}-\mathrm{Co}(4: 1) / \mathrm{C}$ and $\mathrm{Pt}-\mathrm{Ni}(2: 1) / \mathrm{C}$. The vertical line shows the angle position of $\operatorname{Pt}(111)$.

(200). The position of these peaks shifted to higher $2 \theta$ angles is an indication of the alloy formation in the $f c c$ structure of

Table 1 Composition, comparison of mean particle size and structural parameters of Pt-based alloy catalysts

\begin{tabular}{|c|c|c|c|c|c|c|}
\hline Catalyst/C & Composition (\%), EDX & Size/nm, TEM & $D(\%)$ & $\operatorname{Size}^{a} / \mathrm{nm}, \mathrm{XRD}$ & $a^{b} / \mathrm{nm}$ & $\mathrm{Pt}-\mathrm{Pt}^{c} / \mathrm{nm}$ \\
\hline $\mathrm{Pt}$ & 100 & $1.75 \pm 1.02$ & 60 & 2.67 & 0.392 & 0.278 \\
\hline $\mathrm{Pt}-\mathrm{Ni}(2: 1)$ & $68.2: 31.8$ & $2.43 \pm 0.92$ & 46 & 2.72 & 0.389 & 0.275 \\
\hline $\mathrm{Pt}-\mathrm{Ni}(1: 1)$ & $45.7: 54.3$ & $2.64 \pm 1.82$ & 43 & 4.20 & 0.387 & 0.274 \\
\hline $\mathrm{Pt}-\mathrm{Co}(4: 1)$ & $81.7: 18.3$ & $2.40 \pm 1.06$ & 46 & 1.92 & 0.388 & 0.274 \\
\hline $\mathrm{Pt}-\mathrm{Co}(2: 1)$ & $66.9: 33.1$ & $2.86 \pm 1.06$ & 40 & 2.84 & 0.386 & 0.273 \\
\hline $\mathrm{Pt}-\mathrm{Co}(1: 1)$ & $47.9: 52.1$ & $2.93 \pm 1.62$ & 39 & 2.55 & 0.384 & 0.271 \\
\hline
\end{tabular}


platinum. No diffraction peaks corresponding to the presence of cobalt $\left(47.40^{\circ}(101)\right)$ or nickel $\left(44.49^{\circ}(111)\right)$, or of their oxides were observed. The structural observations by TEM and XRD of our samples either heat-treated or not show that the alloy synthesis, via the carbonyl chemical route, is the result of a molecular chemical precursor: $\left[\mathrm{Pt}_{3 / 2} \mathrm{M}_{3 / 2}(\mathrm{CO})_{6}\right]_{n}{ }^{2-}$, as schematized by the chemical equation (see Experimental section). Some relevant structural data, such as crystallite size, using the Debye-Scherrer equation, and mean-interatomic $\mathrm{Pt}-\mathrm{Pt}$ distance are summarized in Table 1. One observes that the calculated particle size values from XRD data are, within experimental errors, in agreement with those obtained by electron microscopy.

\subsection{Electrochemical surface characterization}

Fig. 4 shows an interval of the cyclic voltammograms, after stabilization, carried out in $0.5 \mathrm{M} \mathrm{H}_{2} \mathrm{SO}_{4}$, on an electrochemical window from 0.06 to $0.4 \mathrm{~V} / \mathrm{RHE}$ with $50 \mathrm{mV} \mathrm{s}^{-1}$, for $\mathrm{Pt} / \mathrm{C}, \mathrm{Pt}-\mathrm{Co} / \mathrm{C}$ and $\mathrm{Pt}-\mathrm{Ni} / \mathrm{C}$, respectively. As shown in Fig. 4, the electrochemical response in the hydrogen region is modified by the presence of the second metal, as also observed by others. ${ }^{8,11,46-48}$ In this potential range, hydrogen adsorbs solely onto platinum sites, the associated charge, $Q_{\mathrm{H}}$, was determined by integration of cyclic voltammetry curves, see Table 2. To calculate the active Pt atoms on the surface (nmol) from $Q_{\mathrm{H}}$, charge associated to a monolayer of hydrogen onto platinum of $210 \mu \mathrm{C} \mathrm{cm}{ }^{-2}$ was taken. ${ }^{49}$ Furthermore, the dispersion, $D$, and a mean density of atoms of $1.415 \times$ $10^{15}$ atoms $\mathrm{cm}^{-2}$ were also used considering that particles are cubooctahedra, i.e., consisting of (111) and (100) surfaces. ${ }^{50}$ The atomic surface composition is deduced from these data (see Table 2). One observes that the surface composition of $\mathrm{Pt}-\mathrm{M}$ which deviates from the bulk composition, deduced via EDX, $c f$. Table 1, is enriched with $\mathrm{M}(\mathrm{M}=\mathrm{Ni}, \mathrm{Co})$.

Besides analyzing the particle morphology, the oxygen reduction reaction (ORR) has been studied in the absence and presence of methanol (see Fig. 5A and B). Fig. 5A depicts a series of current-potential curves for Pt, Pt-Ni (2:1) and $\mathrm{Pt}-\mathrm{Co}(4: 1)$ using the rotating disk electrode technique at

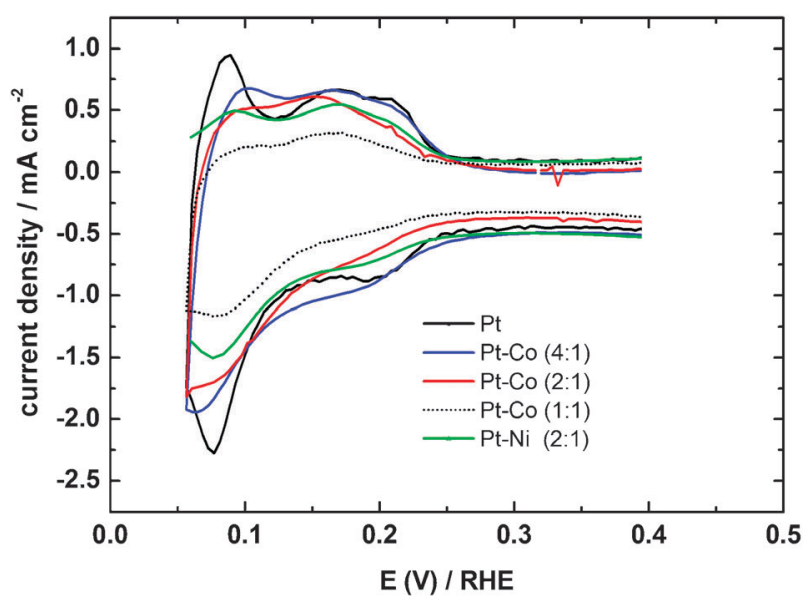

Fig. 4 Voltammograms in $0.5 \mathrm{M} \mathrm{H}_{2} \mathrm{SO}_{4}$ at $50 \mathrm{mV} \mathrm{s}^{-1}$ of $20 \mathrm{wt} \%$ $\mathrm{Pt} / \mathrm{C}, 20 \mathrm{wt} \% \mathrm{Pt}-\mathrm{Co}(1: 1) / \mathrm{C}, 20 \mathrm{wt} \% \mathrm{Pt}-\mathrm{Co}(2: 1) / \mathrm{C}, 20 \mathrm{wt} \% \mathrm{Pt}-\mathrm{Co}$ (4: 1$) / \mathrm{C}$ and $20 \mathrm{wt} \% \mathrm{Pt}-\mathrm{Ni}(2: 1) / \mathrm{C}$.
Table 2 Surface composition deduced by the hydrogen accessibility onto the platinum surface, and $\mathrm{CH}_{3} \mathrm{OH}$ oxidation peak intensity. (a) not measured

\begin{tabular}{|c|c|c|c|c|}
\hline Catalyst/C & $Q_{\mathrm{H}} / \mathrm{mC}$ & $\begin{array}{l}\text { Active Pt atoms } \\
\text { on the surface } \\
\text { from } Q_{\mathrm{H}} / \mathrm{nmol}\end{array}$ & $\begin{array}{l}\text { Atomic } \\
\text { surface } \\
\text { composition }\end{array}$ & $\begin{array}{l}\mathrm{CH}_{3} \mathrm{OH} \text { oxidation } \\
\text { current peak/ } \\
\mathrm{mA} \mathrm{cm}-2\end{array}$ \\
\hline $\mathrm{Pt}$ & 2.20 & 14.73 & 100 & 5.7 \\
\hline $\mathrm{Pt}-\mathrm{Ni}(2: 1)$ & 1.46 & 7.53 & $51: 49$ & 3.6 \\
\hline Pt-Ni $(1: 1)$ & 1.17 & 1.18 & $38: 62$ & (a) \\
\hline $\mathrm{Pt}-\mathrm{Co}(4: 1)$ & 1.76 & 9.04 & $61: 39$ & 4.5 \\
\hline $\mathrm{Pt}-\mathrm{Co}(2: 1)$ & 1.54 & 6.87 & $47: 53$ & 3.7 \\
\hline $\mathrm{Pt}-\mathrm{Co}(1: 1)$ & 0.99 & 4.32 & $29: 71$ & 1.6 \\
\hline
\end{tabular}

$900 \mathrm{rpm}$. Very similar current-potential curves were obtained with other alloy compositions, indicating that the presence of any non-platinum atoms segregated at the surface is not detrimental for the ORR. Moreover, the situation is different when methanol is present as shown in Fig. 5B, since it is well known that the presence of methanol depolarizes significantly the ORR. Indeed, the current-potential characteristic of oxygen reduction in the $0.5 \mathrm{M} \mathrm{H}_{2} \mathrm{SO}_{4}+0.1 \mathrm{M} \mathrm{CH}_{3} \mathrm{OH}$ electrolyte at $20 \mathrm{mV} \mathrm{s}^{-1}$ under quiescent conditions reveals
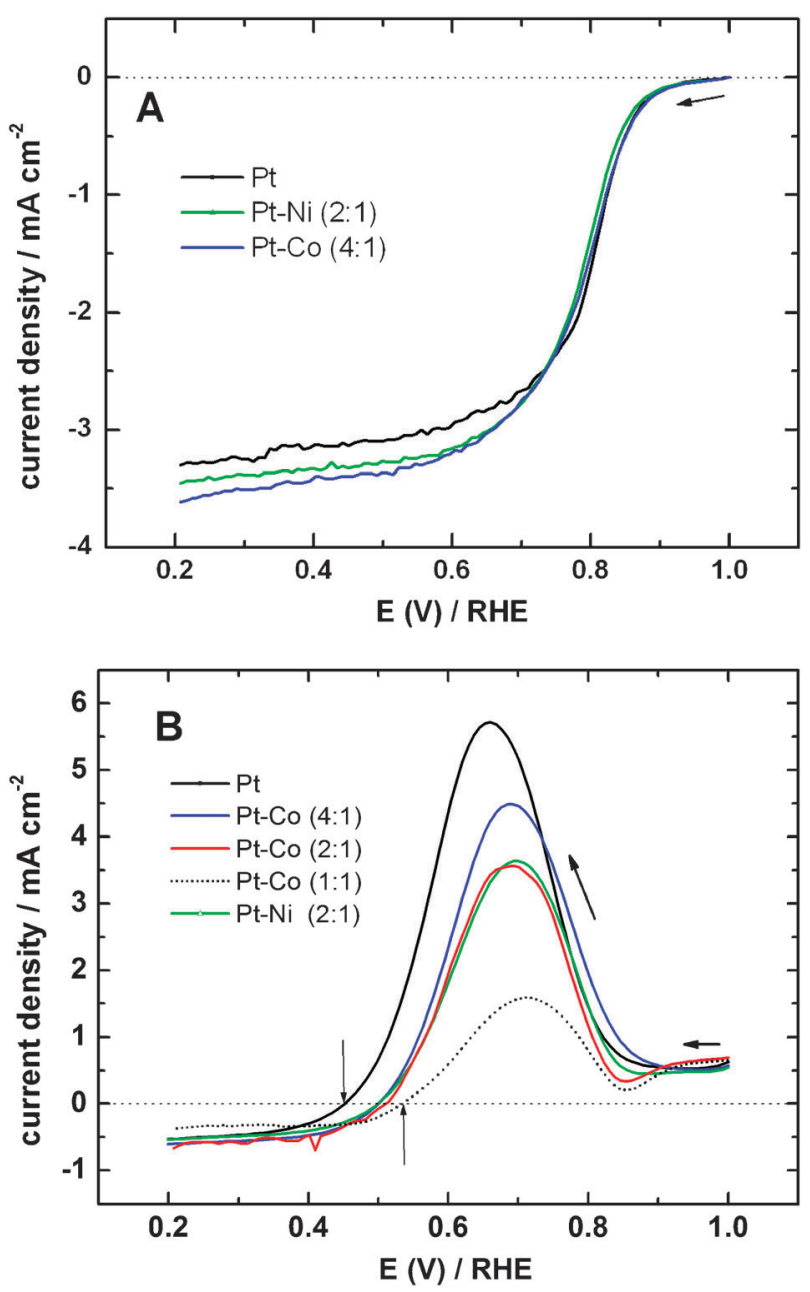

Fig. 5 (A) Rotating Disk Electrode (RDE) current-potential curves for the oxygen reduction in $0.5 \mathrm{M} \mathrm{H}_{2} \mathrm{SO}_{4}$ saturated with $\mathrm{O}_{2}$ at $5 \mathrm{mV} \mathrm{s}^{-1}$ at $900 \mathrm{rpm}$. (B) Linear voltammograms for the oxygen reduction reaction (ORR) in $0.5 \mathrm{M} \mathrm{H}_{2} \mathrm{SO}_{4}+0.1 \mathrm{M} \mathrm{CH}_{3} \mathrm{OH}$ saturated with $\mathrm{O}_{2}$ at $20 \mathrm{mV} \mathrm{s}^{-1}$. Arrows show the scanning direction. 
that atomic surface composition ( $c f$. Table 2) modulates the degree of tolerance of $\mathrm{Pt}$. The methanol oxidation peak decreases in the order $\mathrm{Pt} / \mathrm{C}>\mathrm{Pt}-\mathrm{Co}(4: 1)>\mathrm{Pt}-\mathrm{Ni}(2: 1)$ and shifts toward positive potential values. Just as for the hydrogen zone, the intensities of the peaks are proportional to the amount of platinum present on the catalyst surface.

Using the same chemical route to synthesize the Pt-M catalyst (with $\mathrm{M}=\mathrm{Cr}$ ), Yang et al. ${ }^{9}$ also found $\mathrm{M}$ segregating to the surface for their particles with an increase in the content on the surface corresponding to that of $\mathrm{M}$. The behavior of these compounds is similar to the one we obtained in the case of ORR in the presence of methanol. For Pt-Cr $(1: 1)$, the methanol peak is reduced to a ratio of 7 and shifted to more positive potentials with respect to the $\mathrm{Pt} / \mathrm{C}$ catalyst. With $\mathrm{Pt}-\mathrm{Co}(1: 1)$, the same behavior is observed, with a ratio of 4 .

For the different $\mathrm{Pt}-\mathrm{M}$ alloys obtained by the carbonyl chemical route (with $\mathrm{M}=\mathrm{Cr}, \mathrm{Ni}$, $\mathrm{Co}$ and $\mathrm{Sn}$ ), two different behaviors are obtained: a segregation of $\mathrm{Pt}$ on the surface, like for $\mathrm{Pt}-\mathrm{Sn}^{39}$ or an increase in the content of $\mathrm{M}$ on the surface for the other metals. ${ }^{9}$

These behaviors are also noticed by different results in XRD: for the addition of $\mathrm{Sn}$ to the platinum, the diffraction peaks are shifted towards lower $2 \theta$ angles and for the $\mathrm{Cr}, \mathrm{Ni}$ and $\mathrm{Co}$, the diffraction peaks are shifted toward higher values. $^{8,9,51}$

Predictions of surface segregation phenomena in bimetallic nanoparticles $\mathrm{Pt}-\mathrm{M}(\mathrm{M}=\mathrm{Ni}, \mathrm{Re}, \mathrm{Mo}),{ }^{52}$ and $\mathrm{Pt}-\mathrm{Co}^{53}$ have also been reported.

\subsection{Theoretical studies on the structure of PtNi and PtCo particles}

Motivated by the experimental measurements on the surface composition of the different Pt-based alloy particles, we investigated the structure as well as the segregation behavior of differently sized (1.0-3.0 nm) $\mathrm{Pt}_{x} \mathrm{Ni}_{1}$ and $\mathrm{Pt}_{x} \mathrm{Co}_{1}(x=1,2,3)$ alloy nanoparticles using ReaxFF, ${ }^{54,55}$ a reactive molecular dynamics (MD), with a self-optimized force field. As described in the method section, $\mathrm{Pt}_{x} \mathrm{Ni}_{1}$ and $\mathrm{Pt}_{x} \mathrm{Co}_{1}(x=1,2,3)$ nanoparticles with $1.5,2.0,2.5$ and $3.0 \mathrm{~nm}$ diameter were annealed to $750,1000,1250$, and $1500 \mathrm{~K}$. These four different particle sizes correspond to a total number of $36,114,297,585$, and 1031 atoms. Fig. 6 exemplarily shows the initial bulktruncated structures for $\mathrm{Pt}_{2} \mathrm{Ni}_{1}$ particles as well as the final relaxed particles after annealing to 1000,1250 , or $1500 \mathrm{~K}$. For in-depth statistical investigations we have chosen the $2.0 \mathrm{~nm}$ nanoparticles of $\mathrm{Pt}_{x} \mathrm{Ni}_{1}$ and $\mathrm{Pt}_{x} \mathrm{Co}_{1}(x=1,2,3)$, whereby for each composition a set of 100 different systems has been investigated. In this case, randomly distributing the corresponding amounts of $\mathrm{Pt}$ and $\mathrm{Ni}$ (or $\mathrm{Co}$ ) atoms in a large simulation box and allowing the interactions between the atoms to form a particle generate the initial structures. Afterwards multiple annealing cycles to $1500 \mathrm{~K}$ for $\mathrm{Pt}$ : Ni and to $750 \mathrm{~K}$ for $\mathrm{Pt}$ : Co alloys were performed.

In the following we will first provide an in-depth discussion for the $\mathrm{Pt}_{x} \mathrm{Ni}_{1}(x=1,2,3)$ systems, followed by a short summary of the results for the $\mathrm{Pt}_{x} \mathrm{Co}_{1}(x=1,2,3)$ alloys. The corresponding analyses for the latter systems can be found in the ESI. $\dagger$

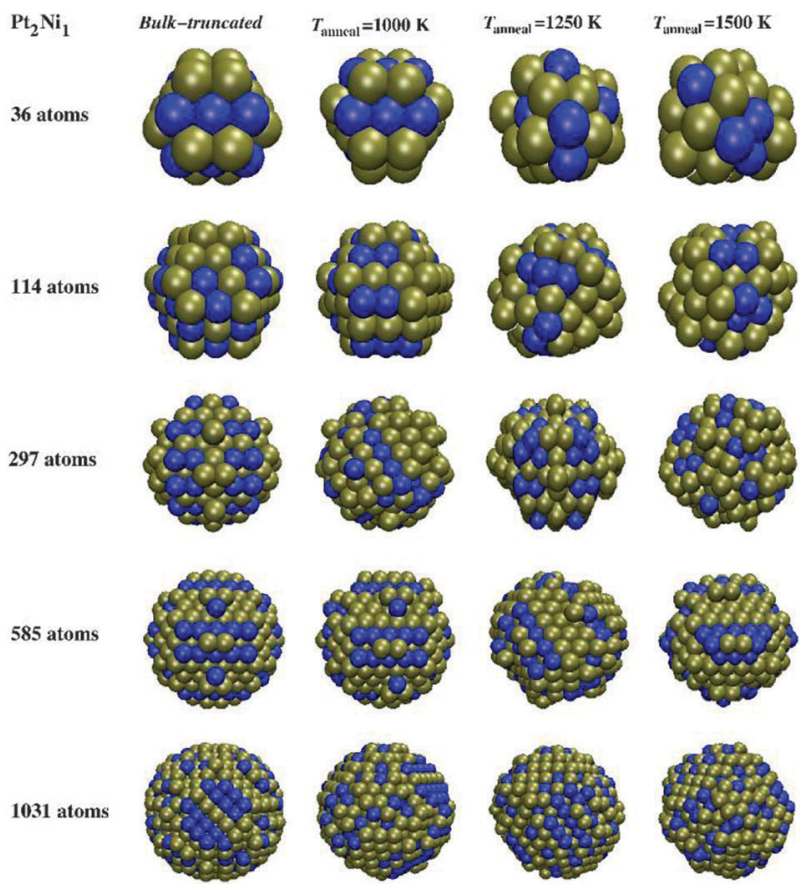

Fig. 6 Hard-sphere models of the $\mathrm{Pt}_{2} \mathrm{Ni}_{1}$ nanoparticles with different diameters. Each column shows the initial bulk-truncated structure as well as the final relaxed particles after annealing to 1000,1250 , or $1500 \mathrm{~K}$. Blue colored atoms represent $\mathrm{Ni}$, while all remaining are $\mathrm{Pt}$.

Using the obtained particles, we first analyzed the distribution of different particle morphologies, i.e. the shape-distribution. As, in principle, every different shape results in a specific overall binding energy of the particle, the latter property has been used for this analysis.

Fig. 7 shows the energy distributions for $\mathrm{Pt}_{x} \mathrm{Ni}_{1}(x=1,2,3)$, where the absolute shift between the curves is caused by the difference in particle mixtures, allowing different amounts of $\mathrm{Pt}-\mathrm{Pt}, \mathrm{Pt}-\mathrm{Ni}$, and $\mathrm{Ni}-\mathrm{Ni}$ bonds. It is interesting that even after multiple annealing cycles at rather high temperatures, each of these curves shows a relatively broad distribution with their maxima near the particular average (dashed vertical lines), indicating that a whole variety of different particle shapes are present even though they do not correspond to the overall global (and thermodynamic) energy minimum morphology

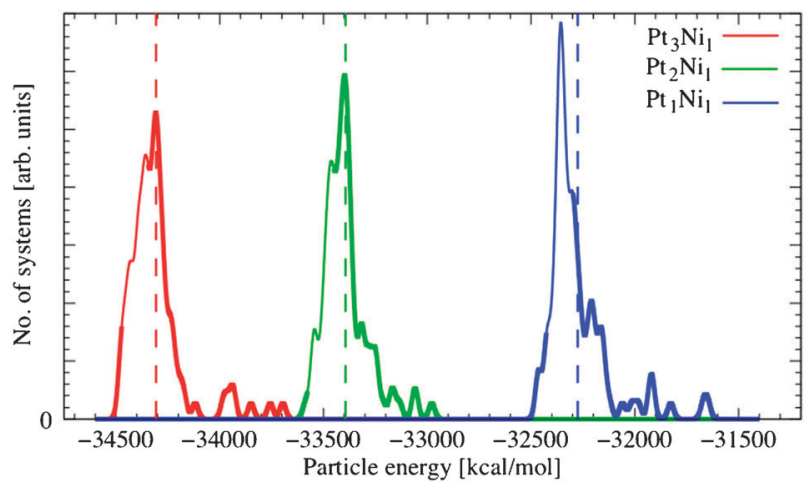

Fig. 7 Energy distributions of the $2.0 \mathrm{~nm} \mathrm{Pt}_{x} \mathrm{Ni}_{1}(x=1,2,3)$ particles obtained after multiple annealing to $1500 \mathrm{~K}$. For each composition the dashed vertical line indicates the average energy. 
given by a Wulff-type particle. Furthermore, out of the statistical sample only a very few set of particles assumed this shape. This example already shows that nanoparticles undergo drastic morphological changes as soon as enough kinetic energy is available, leading to a wide variety of mostly non-Wulff-type cluster structures which we can assume to have different catalytic properties. The final particle structure certainly depends on the procedure of the annealing simulation (i.e., temperature, speed of heating and cooling down, etc.). Therefore, only a rather small portion of nanoparticles assumes the global minimum configuration. However, in a real system one should expect a broad distribution of particle sizes and shapes. This behavior has also been observed experimentally, for instance with $\mathrm{Ag}$ particles on a $\mathrm{SiO}_{2}$ support. ${ }^{56}$

We then analyzed the distribution of $\mathrm{Pt}$ and $\mathrm{Ni}$ atoms within the particles, which in principle should reflect potential segregation effects. Fig. 8 shows the ratio of $\mathrm{Ni}$ atoms versus $\mathrm{Pt}$ atoms separately analyzed for the surface and the bulk. For a homogeneous distribution of $\mathrm{Pt}$ and $\mathrm{Ni}$ within the particles one should expect a $\mathrm{Ni}$ : Pt bulk ratio of $0.33,0.5$, and 1.0 for $\mathrm{Pt}_{3} \mathrm{Ni}_{1}, \mathrm{Pt}_{2} \mathrm{Ni}_{1}$, and $\mathrm{Pt}_{1} \mathrm{Ni}_{1}$, respectively. However, our simulations show drastic deviations from this behavior (see the top plot of Fig. 8). In all cases the amount of Ni in the bulk seems to be increased compared to the overall particle composition, indicating a certain Pt surface segregation.

This effect seems to be more pronounced for $\mathrm{Pt}_{3} \mathrm{Ni}_{1}$, where the ratio increases by roughly $50 \%$ to $\sim 0.5$. For $\mathrm{Pt}_{2} \mathrm{Ni}_{1}$

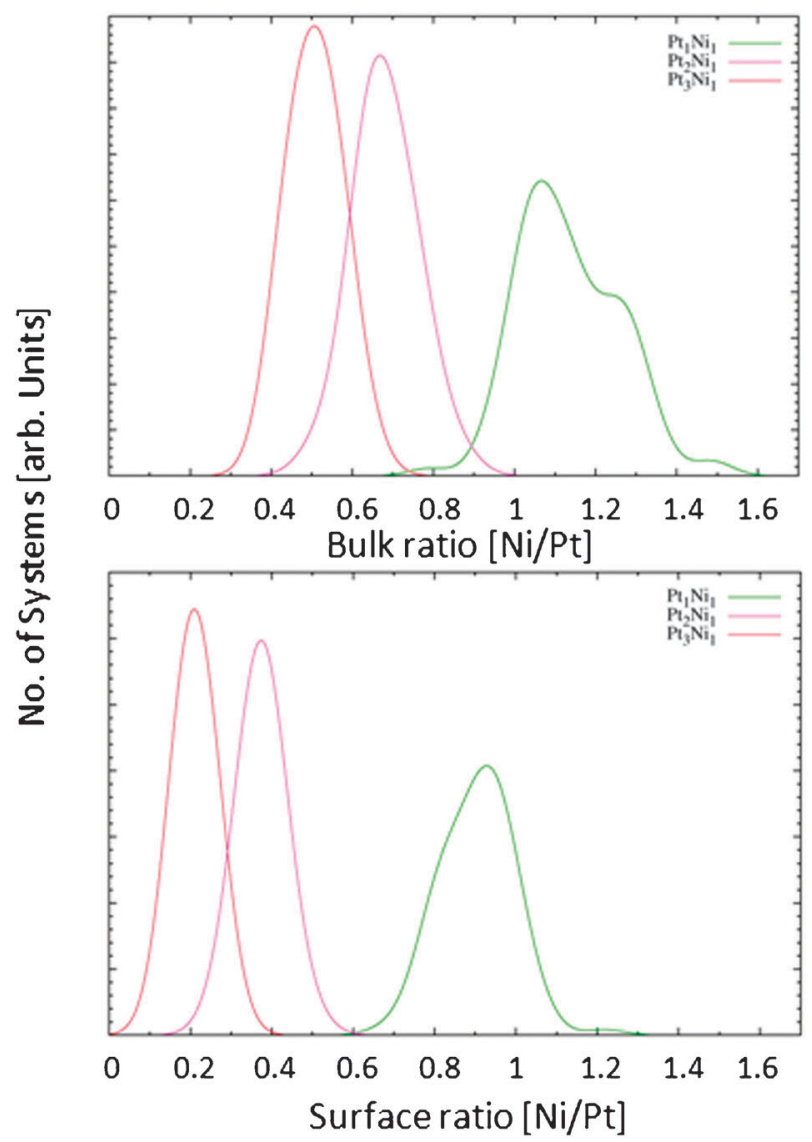

Fig. 8 Ratio between $\mathrm{Ni}$ and $\mathrm{Pt}$ in the bulk (top) and at the surface (bottom) for all $2.0 \mathrm{~nm} \mathrm{Pt}_{x} \mathrm{Ni}_{1}(x=1,2,3)$ particles. and $\mathrm{Pt}_{1} \mathrm{Ni}_{1}$ particles this increase is only $30 \%$ and $15 \%$, respectively, which already shows that the strength of the surface segregation effect depends on the bulk composition of the particles.

Furthermore, the nanoparticle surfaces are composed of faces with different orientations, which usually have their particular segregation behavior, the entire surface is not composed of $\mathrm{Pt}$, but shows a certain, though reduced, amount of Ni atoms. This reduction is clearly seen in the bottom plot of Fig. 8 that shows the averaged Ni : Pt ratio at the particle surface. The segregation behavior is illustrated with a $2 \mathrm{~nm}$ $\mathrm{Pt}_{2} \mathrm{Ni}_{1}$ particle that had been multiple annealed to $1000 \mathrm{~K}$. (111) faces are fully covered with $\mathrm{Pt},(110)$ and (100) planes still contain certain amounts of Ni (see Fig. 9). Between the latter two surface orientations, the (110) planes seem to be dominated by Ni surface segregation. However, as the particle surfaces usually have more (111) than (110) or (100) faces, we obtain the overall segregation behavior shown in Fig. 8, which is in agreement with the behavior observed experimentally for different $\mathrm{Pt}_{x} \mathrm{Ni}_{y}$ single crystal surfaces. ${ }^{57-60}$

Finally, we have analyzed the atom coordination in the bulk and at the surface to obtain a qualitative understanding of the bulk morphology and the surface faces of the nanoparticles. Fig. 10 shows the corresponding structural analysis. The top plot indicates that all particles have a pronounced maximum at a coordination number of 12 , which we found to be due to $f c c$-like bulk morphologies. However, some of the bulk atoms (especially $\mathrm{Pt}$ ) also have higher coordination numbers of 13 or even 14, which is due to some distortions within the particles's cores as well as the cutoff bond distance of $3.2 \AA$ used in our analysis.

We have also repeated the analyses with different bond distance cutoffs, but found the most reliable behavior for $3.2 \AA$. Small changes around this value only led to minor changes in the curve. The surface atoms show a relatively broad distribution of coordination numbers around 8-9. While for an atom of a (111) face one would expect a coordination of 9 , atoms in (110) and (100) planes should be 6-fold and 8-fold coordinated, respectively. The averaged behavior shown in

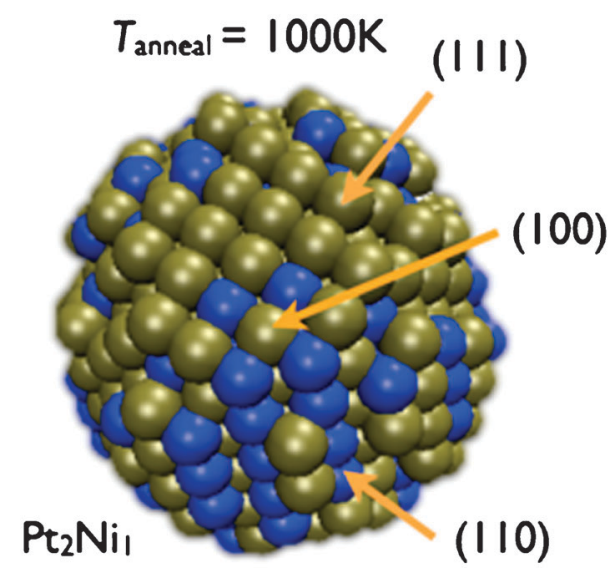

Fig. 9 Hard-sphere model of a representative $2 \mathrm{~nm} \mathrm{Pt}_{2} \mathrm{Ni}_{1}$ particle after multiple annealing to $1000 \mathrm{~K}$. The system shows that the different low-index surfaces have deviating segregation properties. Blue colored atoms represent $\mathrm{Ni}$, while all remaining atoms are $\mathrm{Pt}$. 


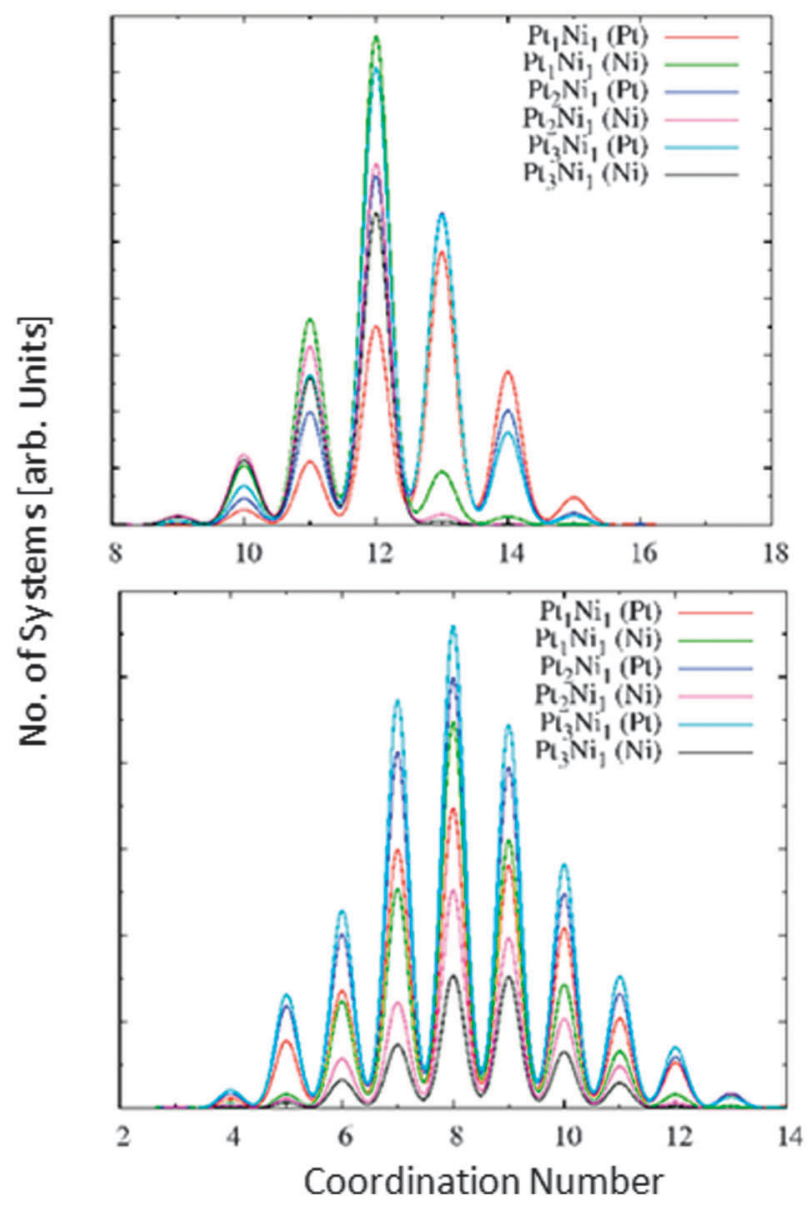

Fig. 10 Atomic coordination of bulk (top) and surface (bottom) atoms for the different $\mathrm{Pt}_{x} \mathrm{Ni}_{1}$ nanoparticles averaged over the 100 investigated particles.

Fig. 10 explains the maximum at $8-9$ as well as the relatively broad distribution. However, it also indicates the overall domination of (111) faces that had already been deduced from the segregation analysis in Fig. 8. Interestingly, for all particle mixtures $\mathrm{Ni}$ atoms tend to prefer coordination numbers of 8 or slightly greater. Taking into account that (111) planes are usually fully covered with $\mathrm{Pt}$, this would mean that Ni prefers (100) planes as well as step edges.

The simulations for the $\mathrm{Pt}_{x} \mathrm{Co}_{1}(x=1,2,3)$ alloys were performed analogous to the $\mathrm{PtNi}$ systems. The in-depth analysis for the $2 \mathrm{~nm}$ particles, which due to the weaker $\mathrm{Pt}-\mathrm{Co}$ interaction was limited to $750 \mathrm{~K}$, shows a similar energy distribution (Fig. S1 in the ESI $\uparrow$ ), being again indicative of a broad variety of particle shapes. In contrast to the $\mathrm{PtNi}$ systems, the $\mathrm{Pt}_{x} \mathrm{Co}_{1}(x=1,2,3)$ nanoalloys show a different segregation behaviour. Analysing the $\mathrm{Pt}$ : Co ratio and the coordination numbers at the particle's surface and bulk (Fig. S2 and S3 in the ESI $\dagger$ ) shows a pronounced surface segregation of Co to the surface of $\mathrm{Pt}_{1} \mathrm{Co}_{1}$ and $\mathrm{Pt}_{2} \mathrm{Co}_{1}$ alloy particles, which is less indicative of $\mathrm{Pt}_{3} \mathrm{Co}_{1}$ particles. This is in qualitative correspondence to the experimental analysis (see Table 2). Interestingly, after annealing some of the particles with higher Co-contents show a phase separation between $\mathrm{Pt}$ and $\mathrm{Co}$, leading to $\mathrm{Pt}$-rich and Co-rich regions within the particle or even two separated Pt and Co particles.
This behaviour can be rationalised by comparing the cohesive energies ${ }^{61}$ of pure $\mathrm{Pt}(5.84 \mathrm{eV})$, pure $\mathrm{Co}(6.89 \mathrm{eV})$ and $\mathrm{Pt}_{3} \mathrm{Co}_{1}$ $(5.51 \mathrm{eV})$. Due to the large difference between the cohesive energies of $\mathrm{Co}$ and $\mathrm{Pt}$ one would expect a tendency of Co-rich PtCo particles to maximize the number of $\mathrm{Co}-\mathrm{Co}$ bonds, which would lead to a phase separation. Certainly, as the Co-content in the alloy particles is reduced, this tendency is weakened. Future work will address exactly this issue.

\subsection{Surface segregation}

Bulk analysis of synthesized materials (Table 1) reflects the nominal atomic composition of PtNi and PtCo alloy catalysts. However, the atom surface ratio by means of hydrogen underpotential deposition $\left(\mathrm{H}_{\text {upd }}\right)$, Fig. 4 , clearly reveals that such ratio is far from expected values. Considering an average particle size of $2.6 \mathrm{~nm}$, the number of atoms within the $f c c$ model (cubo-octahedral structure) is 621 , where $43 \%$ (270) are surface atoms. Rationalizing these figures, $H_{\text {upd }}$ shows that $\mathrm{Pt}$, $\mathrm{Ni}$ and $\mathrm{Co}$ atoms are all distributed at the surface far from the theoretical nominal value. Indeed, on all nanoalloy samples the general trend is that a surface segregation phenomenon takes place. This experimental observation validates the calculations depicted in Fig. 8 (bottom), e.g., for $\mathrm{Pt}_{x} \mathrm{Ni}(x=2)$. While our MD simulations reveal a tendency for Pt to segregate to the surface of PtNi alloys, for PtCo alloys we find the opposite trend, namely Co surface segregation. This is in agreement with our experiments showing that cobalt atoms preferentially segregate to the surface for $\operatorname{PtCo}(2: 1)$ and $(1: 1)$. On the other hand, the tolerance towards methanol during the ORR process is the best, as observed for $\mathrm{Pt}$ : Co $(1: 1) c f$. Fig. 5B, for a slight increase of cobalt surface atoms.

\section{Conclusions}

In this work, Pt, PtCo and PtNi catalysts were synthesized by the chemical carbonyl route. The physical-chemical characterizations strongly support the fact that this route of synthesis favors nanoalloy formation at the molecular level. The change of the $\mathrm{Pt}-\mathrm{Pt}$ mean distance in the Pt : M product gives an account of the same phenomenon. However, the atom distribution at the particles' surface is determined by the size and alloy $\mathrm{Pt} / \mathrm{M}$ ratio. This latter was assessed by surface electrochemistry, clearly indicating the surface segregation phenomenon. An insight into this phenomenon was provided by molecular dynamics simulations, indicating a tendency of Pt surface segregation for the $\mathrm{Pt}-\mathrm{Ni}$ alloys and Co surface segregation for $\mathrm{Pt}-\mathrm{Co}$ alloys, both being dependent on the $\mathrm{Pt}: \mathrm{M}$ ratio of the alloys. From materials point of view, it is clear that the present material improved, to some extent, the tolerance to methanol, although they probably do not fulfill the electronic conditions for a full selectivity. Nevertheless, the way to improve platinum by diluting it in such alloys seems feasible via the carbonyl chemical route for the oxygen reduction reaction process.

\section{Acknowledgements}

D.F, J.A., and T.J. gratefully acknowledge the support of the Deutsche Forschungsgemeinschaft (DFG)-Emmy-NoetherProgram. 


\section{Notes and references}

1 H. A. Gasteiger, S. S. Kocha, B. Sompalli and F. T. Wagner, Appl. Catal., B, 2005, 56, 9-35.

2 H. A. Gasteiger, J. E. Panels and S. G. Yan, J. Power Sources, 2004, 127, 162-171.

3 R. Benítez, A. M. Chaparro and L. Daza, J. Power Sources, 2005, 151, 2-10.

4 A. B. Anderson, Electrochim. Acta, 2003, 48, 3743-3749.

5 R. R. Adzic, J. Zhang, K. Sasaki, M. B. Vukmirovic, M. Shao, J. X. Wang, A. U. Nilekar, M. Mavrikakis, J. A. Valerio and F. Uribe, Top. Catal., 2007, 46, 249-262.

6 K. C. Neyerlin, W. B. Gu, J. Jorne and H. A. Gasteiger, J. Electrochem. Soc., 2007, 154, B631-B635.

7 J. Jiang and B. Yi, J. Electroanal. Chem., 2005, 577, 107-115.

8 H. Yang, W. Vogel, C. Lamy and N. Alonso-Vante, J. Phys. Chem. $B, 2004,108,11024-11034$.

9 H. Yang, N. Alonso-Vante, J. M. Léger and C. Lamy, J. Phys. Chem. B, 2004, 108, 1938-1947.

10 U. A. Paulus, A. Wokaun, G. G. Scherer, T. J. Schmidt, V. Stamenkovic, V. Radmilovic, N. M. Markovic and P. N. Ross, J. Phys. Chem. B, 2002, 106, 4181-4191.

11 H. R. Colón-Mercado and B. N. Popov, J. Power Sources, 2006, 155, 253-263.

12 M. Shao, P. Liu, J. Zhang and R. Adzic, J. Phys. Chem. B, 2007, 111, 6772-6775.

13 U. Bardi, G. A. Somorjai and P. N. Ross, J. Catal., 1984, 85, 272-276.

14 T. Bligaard and J. K. Nørskov, Electrochim. Acta, 2007, 52, $5512-5516$.

15 J. X. Wang, H. Inada, L. Wu, Y. Zhu, Y. Choi, P. Liu, W.-P. Zhou and R. R. Adzic, J. Am. Chem. Soc., 2009, 131, 17298-17302.

16 J. Greeley, W. R. Krekelberg and M. Mavrikakis, Angew. Chem., Int. Ed., 2004, 43, 4296-4300.

17 C. A. Lucas, N. M. Markovic and P. N. Ross, Surf. Sci., 2000, 448, 77-86.

18 S. Mukerjee, J. Appl. Electrochem., 1990, 20, 537-548.

19 H. Bönnemann, G. Braun, W. Brijoux, R. Brinkmann, A. S. Tilling, K. Seevogel and K. Siepen, J. Organomet. Chem., 1996, 520, 143-162.

20 B. Veisz, L. Tóth, D. Teschner, Z. Paál, N. Gyorffy, U. Wild and R. Schlögl, J. Mol. Catal. A: Chem., 2005, 238, 56-62.

21 R. C. Koffi, C. Coutanceau, E. Garnier, J. M. Léger and C. Lamy, Electrochim. Acta, 2005, 50, 4117-4127.

22 N. Toshima and Y. Wang, Langmuir, 1994, 10, 4574-4580.

23 P. Hernandez-Fernandez, S. Rojas, P. Ocon, J. L. GomezdelaFuente, J. SanFabian, J. Sanza, M. A. Pena, F. J. Garcia-Garcia, P. Terreros and J. L. G. Fierro, J. Phys. Chem. C, 2007, 111, 2913-2923.

24 S. Eriksson, U. Nylén, S. Rojas and M. Boutonnet, Appl. Catal., A, 2004, 265, 207-219.

25 H. H. Ingelsten, R. Bagwe, A. Palmqvist, M. Skoglundh, C. Svanberg, K. Holmberg and D. O. Shah, J. Colloid Interface Sci., 2001, 241, 104-111.

26 X. Zhang, K.-Y. Tsang and K.-Y. Chan, J. Electroanal. Chem., 2004, 573, 1-9.

27 L. Xiong and A. Manthiram, Electrochim. Acta, 2004, 49, 4163-4170.

28 A. Habrioux, W. Vogel, M. Guinel, L. Guetaz, K. Servat, B. Kokoh and N. Alonso-Vante, Phys. Chem. Chem. Phys., 2009, 11, 3573-3579.

29 G. Longoni and P. Chini, J. Am. Chem. Soc., 1976, 98, 7225-7231.

30 J. C. Calabrese, L. F. Dahl, P. Chini, G. Longoni and S. Martinengo, J. Am. Chem. Soc., 1974, 96, 2614-2616.

31 N. Alonso-Vante, Fuel Cells, 2006, 6, 182-189.
32 O. Solorza-Feria, K. Ellmer, M. Giersig and N. Alonso-Vante, Electrochim. Acta, 1994, 39, 1647-1653.

$33 \mathrm{~V}$. Le Rhun and N. Alonso-Vante, J. New Mater. Electrochem. Syst., 2000, 3, 331-336.

34 W. Vogel, V. Le Rhun, E. Garnier and N. Alonso-Vante, J. Phys. Chem. B, 2001, 105, 5238-5243.

35 S. Mokrane, L. Makhloufi and N. Alonso-Vante, ECS Trans., 2008, 6, 93-103.

36 C. Delacote, Y. Feng and N. Alonso-Vante, in Catalysts for Oxygen Electroreduction - Recent Developments and New Directions, ed. T. He, Transworld Research Network, Kerala, 2009, vol. 10, pp. 231-252.

37 N. Alonso-Vante, in Catalysis and Electrocatalysis at Nanoparticle Surfaces, ed. A. Wieckowski, E. R. Savinova and C. G. Vayenas, Marcel Dekker, Inc., New York, Basel, 2003, pp. 931-958.

38 N. Alonso-Vante, Pure Appl. Chem., 2008, 80, 2103-2114.

39 A. C. Boucher, N. Alonso-Vante, F. Dassenoy and W. Vogel, Langmuir, 2003, 19, 10885-10891.

40 T. Jacob, R. P. Muller and W. A. Goddard, J. Phys. Chem. B, 2003, 107, 9465-9476.

41 T. Jacob, B. V. Merinov and W. A. Goddard Iii, Chem. Phys. Lett., 2004, 385, 374-377.

42 T. Jacob and W. A. Goddard, J. Phys. Chem. B, 2004, 108, $8311-8323$.

43 W. Goddard Iii, B. Merinov, A. Van Duin, T. Jacob, M. Blanco, V. Molinero, S. S. Jang and Y. H. Jang, Mol. Simul., 2006, 32, 251-268.

44 T. Jacob and W. A. Goddard III, ChemPhysChem, 2006, 7, 992-1005.

45 A. Borodzinski and M. Bonarowska, Langmuir, 1997, 13, $5613-5620$.

46 M. T. Paffett, J. G. Beery and S. Gottesfeld, J. Electrochem. Soc., 1988, 135, 1431-1436.

47 U. A. Paulus, A. Wokaun, G. G. Scherer, T. J. Schmidt, V. Stamenkovic, N. M. Markovic and P. N. Ross, Electrochim. Acta, 2002, 47, 3787-3798.

48 T. Frelink, W. Visscher and J. A. R. van Veen, Electrochim. Acta, 1995, 40, 545-549.

49 A. Pozio, M. De Francesco, A. Cemmi, F. Cardellini and L. Giorgi, J. Power Sources, 2002, 105, 13-19.

50 B. Veisz, Z. Kiraly, L. Toth and B. Pecz, Chem. Mater., 2002, 14, 2882-2888.

51 Q. Huang, H. Yang, Y. Tang, T. Lu and D. L. Akins, Electrochem. Commun., 2006, 8, 1220-1224.

52 G. Wang, M. A. Van Hove, P. N. Ross and M. I. Baskes, Prog. Surf. Sci., 2005, 79, 28-45.

53 Y. H. Chui and K.-Y. Chan, Chem. Phys. Lett., 2005, 408, 49-53.

54 A. C. T. van Duin, S. Dasgupta, F. Lorant and W. A. Goddard, J. Phys. Chem. A, 2001, 105, 9396-9409.

55 T. T. Järvi, A. Kuronen, M. Hakala, K. Nordlund, A. C. T. Van Duin, W. A. Goddard Iii and T. Jacob, Eur. Phys. J. B, 2008, 66 , 75-79.

56 S. S. Dang, T. Jacob, T. W. Hansen, D. Wang, R. Schlögl, B. Freitag and S. Kujawa, Angew. Chem., Int. Ed., 2008, 47, 5005-5008.

57 M. A. Vasiliev, J. Phys. D: Appl. Phys., 1997, 30, 3037-3070.

58 M. Lundberg, Phys. Rev. B, 1987, 36, 4692-4699.

59 Y. Gauthier, Y. Joly, R. Baudoing and J. Rundgren, Phys. Rev. B, 1985, 31, 6216-6218.

60 U. Bardi, B. C. Beard and P. N. Ross, J. Catal., 1990, 124, 22-29.

61 X.-J. Ge, N.-X. Chen, W.-Q. Zhang and F.-W. Zhu, J. Appl. Phys., $1999, \mathbf{8 5}, 3488-3493$ 